\title{
Multicolour interphase cytogenetics: 24 chromosome probes, 6 colours, 4 layers
}

\author{
D. Ioannou ${ }^{\mathrm{a}}$, E.J. Meershoek ${ }^{\mathrm{b}}$, A.R. Thornhill ${ }^{\mathrm{a}, \mathrm{c}}$, M. Ellis ${ }^{\mathrm{d}}$, D.K. Griffin ${ }^{\mathrm{a}, *}$ \\ ${ }^{a}$ School of Biosciences, University of Kent, Giles Lane, CT2 7NJ, Canterbury, UK \\ ${ }^{\mathrm{b}}$ Kreatech Diagnostics, 1032 LG, Amsterdam, The Netherlands \\ ${ }^{\mathrm{c}}$ The London Bridge Fertility, Gynaecology and Genetics Centre, SE1 9RY, London, UK \\ ${ }^{\mathrm{d}}$ Digital Scientific UK, Cambridge, CB3 OAX, UK
}

\section{A R T I C L E I N F O}

\section{Article history:}

Received 7 June 2011

Received in revised form

19 July 2011

Accepted 16 August 2011

Available online $\mathrm{xxx}$

\section{Keywords:}

FISH

Multicolour

Aneuploidy

Infertility

Nuclear organisation

\begin{abstract}
A B S T R A C T
From the late 1980s onwards, the use of DNA probes to visualise sequences on individual chromosomes (fluorescent in-situ hybridisation - FISH) revolutionised the study of cytogenetics. Following single colour experiments, more fluorochromes were added, culminating in a 24 colour assay that could distinguish all human chromosomes. Interphase cytogenetics (the detection of chromosome copy number in interphase nuclei) soon followed, however 24 colour experiments are hampered for this application as mixing fluorochromes to produce secondary colours produces images that are not easily distinguishable from overlapping signals. This study reports the development and use of a novel protocol, new fast hybridising FISH probes, and a bespoke image capture system for the assessment of chromosome copy number in interphase nuclei. The multicolour probe sets can be used individually or in sequential hybridisation layers to assess ploidy of all 24 human chromosomes in the same nucleus. Applications of this technique are in the investigation of chromosome copy number and the assessment of nuclear organisation for a range of different cell types including human sperm, cancer cells and preimplantation embryos.
\end{abstract}

(c) 2011 Elsevier Ltd. All rights reserved.

\section{Introduction}

From the late 1980s onwards fluorescent in-situ hybridisation (FISH) revolutionised cytogenetics (e.g. [43]) by providing the ability to light up individual chromosome regions at will. FISH found applications in gene mapping [31], clinical diagnostics [16,26], comparative genomics $[2,57]$ and basic chromosome research. Dualcolour FISH on metaphase chromosomes arrived in the early 1990s as the use of a single hapten (usually biotin) was accompanied by a second (usually digoxigenin) both detected with a different fluorochrome. The advent of direct labelling approaches however opened the way for multicolour applications, making it possible to use more and more chromosomes with three [39] four and more fluorochromes being used in single experiments. It was soon realised that mixing of colours led to further probe combinations and, shortly thereafter, 12 colours [6] were reported. In an increasingly fraught race to produce a 24 chromosome combination, two groups reported 24 colour chromosome painting [51,52]. Simpler, cost-effective means of producing 24 colour paints followed (e.g. [46]) and commercial companies began to market them such that it is now possible to purchase 24 chromosome combination probes for around $\$ 10,000$ for 10 test reactions.

\footnotetext{
* Corresponding author. Tel.: +44 01227 823022; fax: +44 01227763912.

E-mail address: d.k.griffin@kent.ac.uk (D.K. Griffin).
}

Interphase cytogenetics by FISH was first introduced by Cremer and colleagues amongst others $[5,9,25,29,43,50]$ and largely found its utility in areas where preparation of metaphase chromosomes was impractical. Principal amongst these applications was cancer diagnostics where it provided a cell by cell chromosome copy number count and, although eventually complemented by comparative genome hybridisation (CGH) [27], the two approaches are still used in combination to this day for research, screening and diagnosis of solid tumours [30]. In reproductive medicine interphase cytogenetics is also very useful. The two relevant areas are the screening of aneuploidy in sperm $[1,18,41,54]$ and preimplantation genetic diagnosis [19,20,35-38].

In recent years, cytogenetics has undergone another revolution with the advent of microarray technology. Either tiling path microrrays [11] or single nucleotide polymorphism arrays (SNP chips) [33,53] have been used to make cytogenetic diagnoses and, in many areas, obviated the need for either karyotyping or FISH $[23,28]$. Array-based approaches are ideal when the cell population in question is homogenous in nature, i.e. all the cells are of the same karyotype. That is, although array CGH or SNP chip diagnosis is possible on single cells $[15,21]$ a cell by cell analysis on anything but a small sample size is prohibitively expensive. Therefore in the fields of cancer diagnosis, sperm aneuploidy screening and the "follow up" of human embryos (i.e. those not used in an IVF cycle), interphase cytogenetics, where a cell by cell copy number karyotype is required, is still arguably the best approach. 
Despite the advances in multicolour FISH on metaphase chromosomes, we are not aware of a simple protocol that will reliably diagnose all 24 human chromosomes in individual nuclei. In our opinion, the principal reason for this is that mixing of fluorochromes to produce secondary colours (commonplace on chromosomes) is not practical as such mixes are not easily distinguishable from overlapping signals. Similarly we are not aware that 24 individual spectrally separable single fluorochromes exist that can be used in a single experiment. Nearly 10 years ago a protocol termed "re-FISH" was introduced [34] that allowed hybridisation of four individual probe layers. It was used to study the organisation of interphase nuclei but not as a means of detecting chromosome copy number reliably. Moreover, fluorochrome colour mixes were used. The purpose of this study was therefore to develop a single assay that could be used to detect 24 chromosome copy number on individual nuclei without the need for mixing colours [34]. A combination of probes, reagents, new protocols as well as novel hardware and software for capture and detection was necessary to make this possible. In this study, we therefore devised and applied a protocol that involved six spectrally distinct fluorochromes (blue, aqua, green, gold, red, far red) plus the DAPI counterstain, and a four layer probing and re-probing strategy. We reasoned that a greater number of fluorochromes would make spectral separation difficult and thus used those that, commercially, are well established as being spectrally distinct. Clearly, less than six colours would lead to a greater number of times the nuclei would need to be re-probed, which could, potentially reduce the chances of hybridisation success in the later steps. From the outset we therefore reasoned that, given that there are 24 different human chromosomes, a $6 \times 4$ (i.e. 6 fluorescent colours, 4 hybridisation layers) would be the best strategy. This approach was performed in human lymphocytes, sperm and preimplantation embryos.

\section{Materials and methods}

Control lymphocytes were from a karyotypically normal male and prepared by standard protocols. Sperm samples were from karyotypically normal donor males at the London Bridge Fertility, Gynaecology and Genetics Centre, UK. Human embryos (25 in total) were surplus to IVF requirements at the London Bridge Fertility Centre, the Lister Fertility Clinic, and the Abumeliana Clinic in Libya. All patients gave informed consent for the use of their lymphocytes, sperm and embryos for these purposes. This work was approved under the treatment license awarded by the HFEA to London Bridge and Lister Fertility clinics, Libyan Ministry of Health, and the local research and Ethics committee of the University of Kent.
Kreatech Diagnostics synthesized all probes for this protocol using the Universal Linkage Labeling System (KBI-40060): http://www. kreatech.com/rest/products/repeat-freetm-poseidontm-fish-dnaprobes/preimplantation-genetic-screening/multistar-24-fish.html.

The presence of highly repetitive sequences (e.g. $\alpha$ satellite) made the centromere an attractive target for the generation of probes for this application as it allowed rapid chromosome detection and generation of bright signals. The use of centromeric probes is commonly seen in FISH studies $[8,13,41,42,49]$ and most companies market centromeric probes either for individual chromosomes or as part of a multiprobe mix (e.g. Kreatech, Abbott Molecular, Cytocell). Centromeric targets were used for 18 out of 24 probes. Since however the centromeres of chromosomes 5 and 19,13 and 21, plus 14 and 22 each share sequence identity with one another their repetitive sequences they could not be distinguished using centromeric targets (that is a probe for these centromeres would light up both chromosomes 13 and 21, 14 and 22, or 5 and 19). Chromosome identifier probes for these six chromosomes were thus combined in a probe set that made use of unique sequence-specific probes. The highly repetitive nature of the remaining unique centromeric targets meant that hybridisation times could be reduced to $15-30 \mathrm{~min}$, however the unique sequence probes required overnight hybridisation. The choice of fluorochromes for each individual probe relied on combining the strongest signals with the least strong fluorochormes and vice versa. For instance chromosome 18 (one of the brightest and most reliable probes) was labelled with the blue (the least bright) fluorochrome. Table 1 illustrates the final probe-fluorochrome combinations. In general terms, the experiments designed to establish the optimum approach focused on whether the unique sequence probe set should be the first or last layer. The overwhelming evidence was in favour of it being the final layer as experiments in which it was the first layer led to unacceptable levels of "no signal" in subsequent hybridisations.

For FISH, nuclei were prepared and fixed to glass slides by standard protocols described previously ([4] for lymphocytes; [22] for blastomeres; [17] for sperm). Slides were briefly washed in PBS, (2 $\mathrm{min}$ ) followed by a short dehydration (70-80-100\% ethanol -3 min each) and air-drying. This preceded pepsin treatment $\left(1 \mathrm{mg} / \mathrm{ml}\right.$ pepsin in $0.001 \mathrm{M} \mathrm{HCl}, 20 \mathrm{~min}$ at $\left.37{ }^{\circ} \mathrm{C}\right)$. Slides were then rinsed in distilled water, then PBS followed by a paraformaldehyde fixation step at $4{ }^{\circ} \mathrm{C}(1 \%$ paraformaldehyde in PBS) for $10 \mathrm{~min}$. Cells were then washed in PBS followed by distilled water, another ethanol series and air-drying. For sperm cells there was an additional swelling step before the pepsin treatment (10 mM DTT $-0.1 \mathrm{M}$ Tris $\mathrm{HCl}-\mathrm{pH} 8.0-400 \mu \mathrm{l}$ of DTT in $40 \mathrm{ml}$ of Tris) at room temperature for 20 min to enhance probe access.

Probe combinations (termed "alpha", "beta", "gamma", and "omega" layers - Table 1) dissolved in hybridisation mix (Kreatech)

Table 1

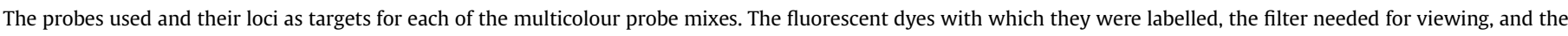

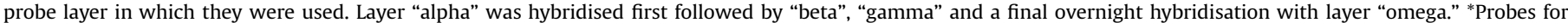
chromosomes 1 and 9 were for highly repetitive heterochromatic regions below the centromere. "SE" stands for satellite enumeration - the Kreatech trade name.

\begin{tabular}{|c|c|c|c|c|c|}
\hline Fluorochrome & Filter & $\begin{array}{l}\text { “Alpha” layer: } \\
\text { centromeric probes }\end{array}$ & $\begin{array}{l}\text { "Beta" layer: } \\
\text { centromeric probes }\end{array}$ & $\begin{array}{l}\text { "Gamma" layer: } \\
\text { centromeric probes }\end{array}$ & $\begin{array}{l}\text { “Omega” layer: } \\
\text { unique sequence probes }\end{array}$ \\
\hline $\begin{array}{l}\text { PlatinumBright }{ }^{\mathrm{TM}} 405 \\
\text { Dark blue }\end{array}$ & Blue & SE 7 (7p11-q11) & SE 11 (11p11-q11) & SE 18 (18p11-q11) & CD37 (19q13) \\
\hline $\begin{array}{l}\text { PlatinumBright } 415 \\
\text { Light blue (aqua) }\end{array}$ & Aqua & SE 1 (1q12)* & $\operatorname{SE} \mathbf{9}(9 q 12)^{*}$ & SE $\mathbf{1 6}$ (16p11-q11) & PDGFRB (5q33) \\
\hline $\begin{array}{l}\text { PlatinumBright } 495 \\
\text { Green }\end{array}$ & Green & SE $6(6 p 11-q 11)$ & SE $\mathbf{2 0}(20 p 11-q 11)$ & SE 2 (2p11-q11) & DSCR (21q22) \\
\hline $\begin{array}{l}\text { PlatinumBright } 547 \\
\text { Light red/orange }\end{array}$ & Gold & SE 8 (8p11-q11) & SE 12 (12p11-q11) & SE $\mathbf{X}(\mathrm{Xp} 11-\mathrm{q} 11)$ & BCR (22q11) \\
\hline $\begin{array}{l}\text { PlatinumBright } 590 \\
\text { Dark red }\end{array}$ & Red & SE 3 (3p11-q11) & SE $\mathbf{1 0}(10 p 11-q 11)$ & SE Y (Yp11-q11) & RB (13q14) \\
\hline $\begin{array}{l}\text { PlatinumBright } 647 \\
\text { Far red }\end{array}$ & Far red & SE 4 (4p11-q11) & SE 17 (17p11-q11) & SE 15 (15p11-q11) & IGH (14q32) \\
\hline
\end{tabular}


were pre-denatured at $72-73{ }^{\circ} \mathrm{C}$ for $10 \mathrm{~min}$ and pipetted on to the target nuclei on the slide. Co-denaturation of probe and target cells $-75{ }^{\circ} \mathrm{C}$ for $90 \mathrm{~s}-$ in a "Thermobrite - (StatSpin/Kreatech) continued before hybridisation at $37{ }^{\circ} \mathrm{C}$. The hybridisation period for the alpha, beta and gamma layers was 15-30 min (in latter experiments, 30 min proved optimum and was used for all layers) whereas, for the omega layer, hybridisation was overnight ( $>16 \mathrm{~h}$ ). Post-hybridisation washes were for $90 \mathrm{~s}$ ( $3 \mathrm{~min}$ for sperm cells) using $0.7 \times$ SSC, $0.3 \%$ Tween 20 at $72{ }^{\circ} \mathrm{C}$ followed by a 2 min wash at $2 \times$ SSC at room temperature. The last step was to dehydrate and air dry the slides then mount them in Vectashield with DAPI (Vector labs) before proceeding to microscope analysis. After visualisation and image capture, slides were washed in $2 \times$ SSC at room temperature to remove the coverslip and then washed for $30 \mathrm{~s}$ in distilled water $\left(72{ }^{\circ} \mathrm{C}\right)$ to remove the bound probe. An ethanol series (dehydration round) preceded air-drying before continuation to the next layer of hybridisation. The protocol was the same for the beta, gamma and omega layers with the following exceptions: a) The overnight hybridisation time for the omega layer (previously mentioned; b) pepsin and paraformaldehyde treatment were only required for the alpha layer; c) the post-hybridisation wash time was consecutively reduced with every layer from $90 \mathrm{~s}$ (alpha layer) to $50-60 \mathrm{~s}$ (beta layer) to $30 \mathrm{~s}$ (gamma and omega layers).

Microscopy analysis was performed on an Olympus BX-61 epifluorescence microscope equipped with a cooled CCD camera (Digital Scientific - Hamamatsu Orca-ER (4742-80) and using the appropriate filters. To enable analysis of seven fluorochromes for image acquisition (six fluorochromes and DAPI counterstain) two communicating filter wheels (Digital Scientific UK) with the appropriate filters were used. The recommended filters by the probe manufacturers can be found here:http://www.kreatech.com/rest/customerservice-support/technical-support/fluorophores-and-filter-recomm endation.html.

All images were acquired using adaptations of SmartCapture software (Digital Scientific UK).

For the above protocol we developed the following hints and tips to ensure accurate hybridisation:

- Probes should be gently mixed (tapping or gentle vortex) and centrifuged before use.

- The temperature of probe denaturation and post-hybridisation washes should not exceed $73{ }^{\circ} \mathrm{C}$.

- The use of a pre-denaturation step for the probes was, we discovered, a crucial one in ensuring the success of the technique.

- Contact with natural light should be minimal.

- Due to the presence of a blue fluorochrome in the probe mix, DAPI concentration should be reduced in order not to prevent the visualisation of the blue signal (blue is visible with a $0.1 \mathrm{ng} / \mu \mathrm{l}$ of DAPI).

- We recommend the following sequence of capturing: Far red, red, green, aqua, gold, blue, counterstain.

- The far red signal can be enhanced by exciting with the DAPI channel and observed immediately after. It is the fastest bleeding signal.

- Always use the blue filter to confirm the aqua-blue signals as blue bleeds in the aqua channel.

- Similarly red and gold should be cross-checked for bleedthrough.

\section{Results}

The probe sets were validated using human lymphocytes as a control from a karyotypically normal male. When applied individually (see Table 2), the efficiency for each probe in each layer in these lymphocyte controls was above $90 \%$ (the ones most prone to showing signal "drop out" were chromosomes $1,11,14$ and 16), with some individual target loci reaching $100 \%$ (e.g. for chromosomes 3 , $6,12, \mathrm{X}$ and $\mathrm{Y}$ ). When our sequential four layer strategy was applied in three separate experiments, the proportion, of cells with 24/24 signals was $60 \%$; with 23/24 cells it was $20 \%$; between 20 and 22 signals was seen in $13.3 \%$ of cells and "no result" (i.e. cells could not be easily analysed) was recorded in $6.7 \%$ of cells ( 100 cells analysed per experiment). From each assay the average percentage of correct ploidy for each of the layers was calculated. For the alpha layer it was $93.3 \%$, for the beta layer it was $83.3 \%$, for the gamma layer it was $83.3 \%$ and for the omega layer it was $76.7 \%$. These numbers were very similar to figures seen when the probes were hybridised individually (Table 2 ) i.e. $90.3 \%, 82.5 \%, 86.4 \%$ and $76.7 \%$ for alpha, beta, gamma and omega probe combinations (Table 2). Also hybridisation efficiencies were similar regardless of which probe set was used in which order, with the exception that our "work-up" experiments identified that the unique sequence probe set (omega) should be the final one to be hybridised. Fig. 1A shows a single lymphocyte nucleus with the four single hybridisation layers on the same nucleus, then the four images merged using Adobe Photoshop (Fig. 1B).

With regard to the sperm heads (Fig. 2), each probe set was used in individual FISH experiments (i.e. without re-probing) and, for each chromosome, hybridisation efficiencies were $100 \%$ (i.e. one signal in each nucleus) in each of the probe sets. Results on 360 human blastomeres from 25 human embryos (e.g. Fig. 3) gave brighter signals than lymphocytes with the nuclei being apparently more resistant to the sequential hybridisation layers. Because of the known high proportion of chromosome abnormalities in human embryos and the fact that mosaicism is commonplace (due to postzygotic chromosome gain and loss) we only noted the efficacy of the hybridisation, not whether the nuclei displayed the "correct number of signals."

Table 2

Hybridisation efficiencies for each probe when used on male lymphocytes (note that the correct number of signals therefore is 1 for the sex chromosomes).

\begin{tabular}{|c|c|c|c|c|}
\hline Chromosome & Two Signals & One Signal & No signal & Success rate \% \\
\hline \multicolumn{5}{|l|}{ Alpha probe set } \\
\hline 7 & 102 & 1 & 0 & 99.0 \\
\hline 1 & 97 & 6 & 0 & 94.1 \\
\hline 6 & 100 & 0 & 0 & 100.0 \\
\hline 8 & 99 & 4 & 0 & 96.1 \\
\hline 3 & 103 & 0 & 0 & 100.0 \\
\hline 4 & 101 & 2 & 0 & 98.0 \\
\hline \multicolumn{4}{|c|}{ Overall success rate: \% of cells with correct ploidy } & 90.3 \\
\hline \multicolumn{5}{|c|}{ Beta probe set } \\
\hline 11 & 98 & 5 & 0 & 95.1 \\
\hline 9 & 98 & 5 & 0 & 95.1 \\
\hline 20 & 101 & 2 & 0 & 98.0 \\
\hline 12 & 103 & 0 & 0 & 100.0 \\
\hline 10 & 102 & 1 & 0 & 99.0 \\
\hline 17 & 98 & 5 & 0 & 95.1 \\
\hline \multicolumn{4}{|c|}{ Overall success rate: \% of cells with correct ploidy } & 82.5 \\
\hline \multicolumn{5}{|c|}{ Gamma probe set } \\
\hline 18 & 100 & 3 & 0 & 97.0 \\
\hline 16 & 96 & 7 & 0 & 93.2 \\
\hline 2 & 99 & 4 & 0 & 96.1 \\
\hline $\mathrm{X}$ & 0 & 103 & 0 & 100.0 \\
\hline Y & 0 & 103 & 0 & 100.0 \\
\hline 15 & 100 & 3 & 0 & 97.0 \\
\hline \multicolumn{4}{|c|}{ Overall success rate: \% of cells with correct ploidy } & 86.4 \\
\hline \multicolumn{5}{|c|}{ Omega probe set } \\
\hline 19 & 100 & 3 & 0 & 97.8 \\
\hline 5 & 99 & 4 & 0 & 96.1 \\
\hline 21 & 102 & 1 & 0 & 99.0 \\
\hline 22 & 101 & 2 & 0 & 98.1 \\
\hline 13 & 99 & 4 & 0 & 96.1 \\
\hline 14 & 93 & 8 & 2 & 90.3 \\
\hline \multicolumn{4}{|c|}{ Overall success rate: \% of cells with correct ploidy } & 76.7 \\
\hline
\end{tabular}


A
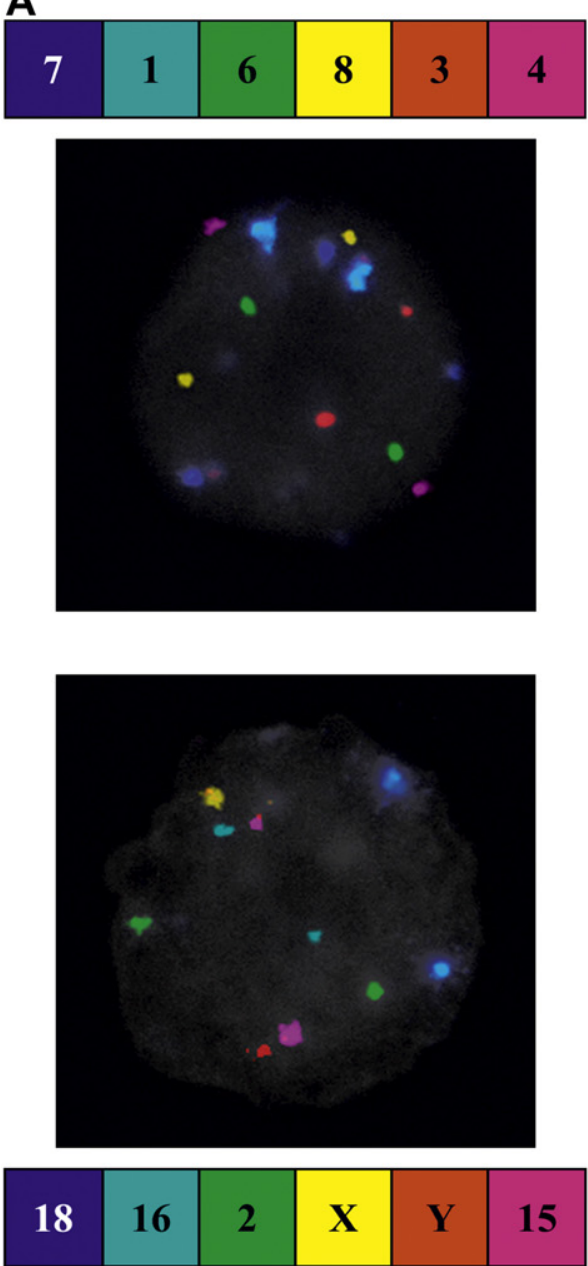
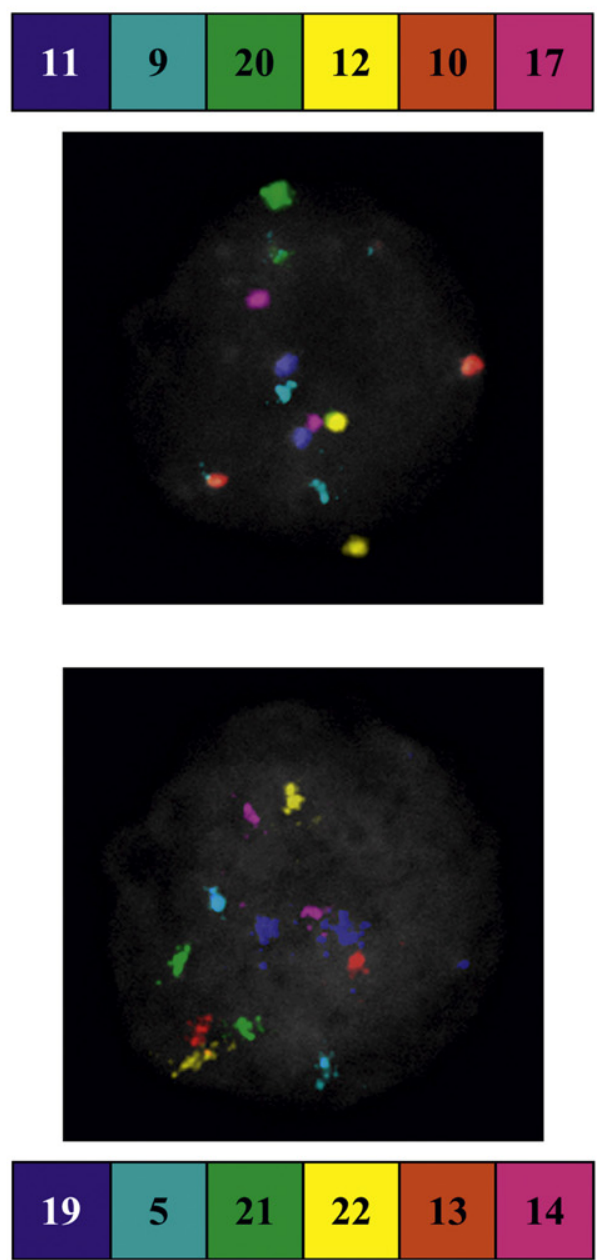

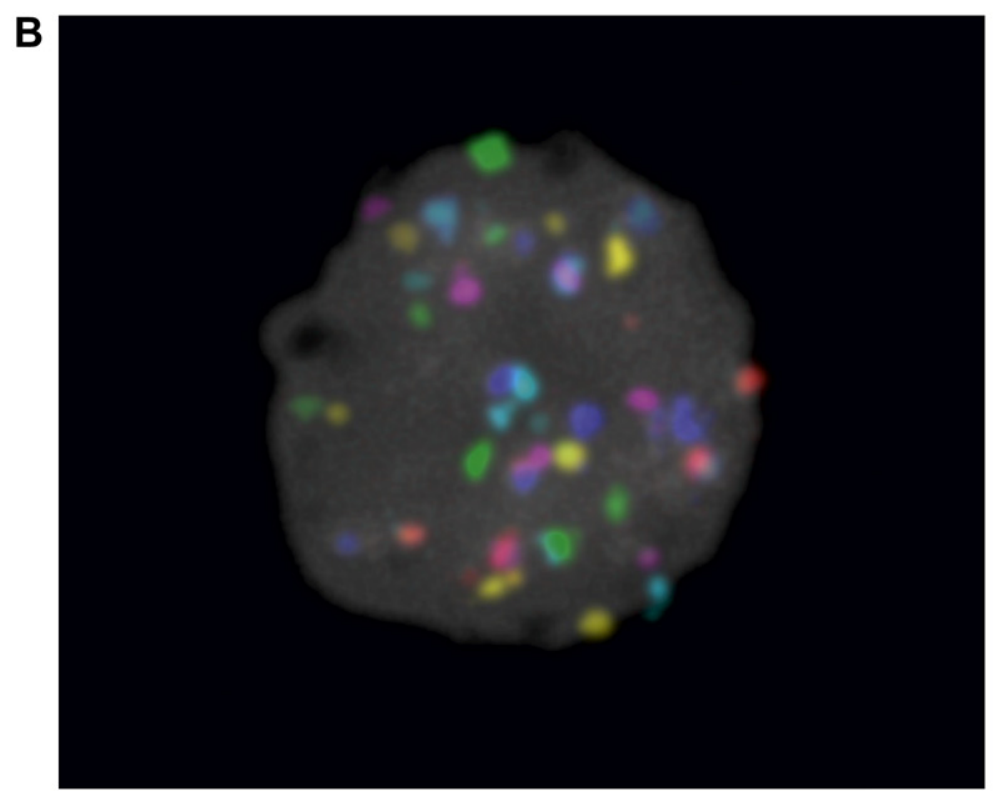

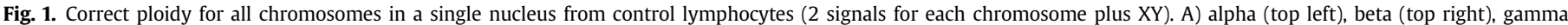
(bottom left) and omega (bottom right) individually; B) Composite image of all four layers merged in Adobe Photoshop. 

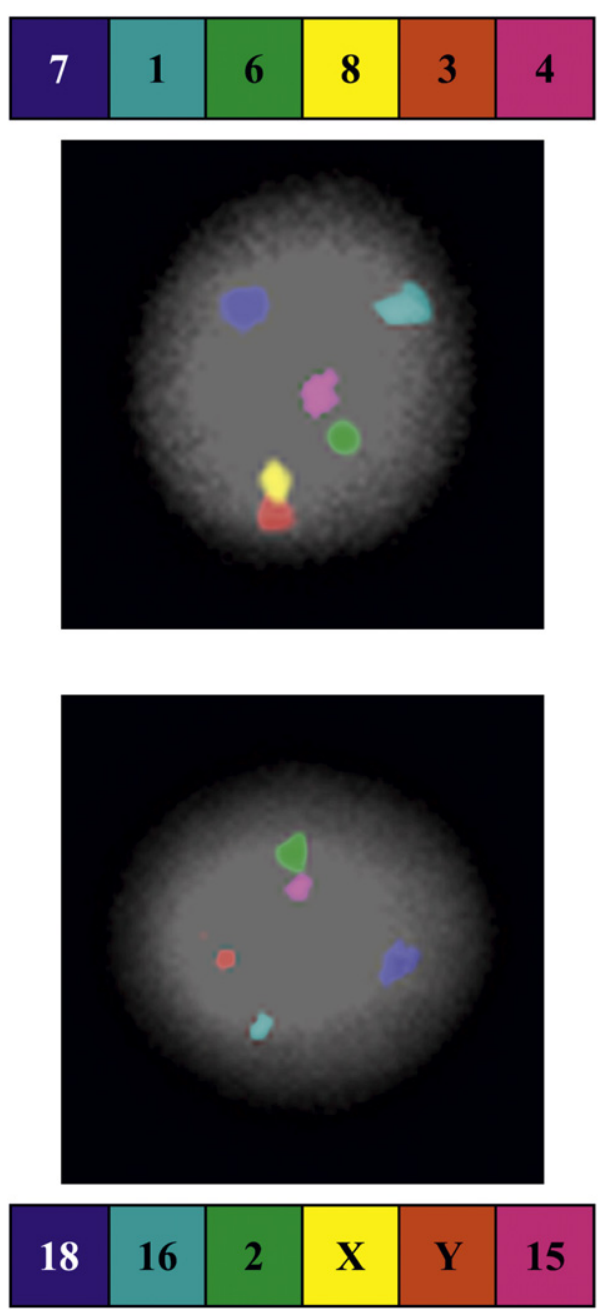

Fig. 2. Signals for each of the probes in four different sperm cells.
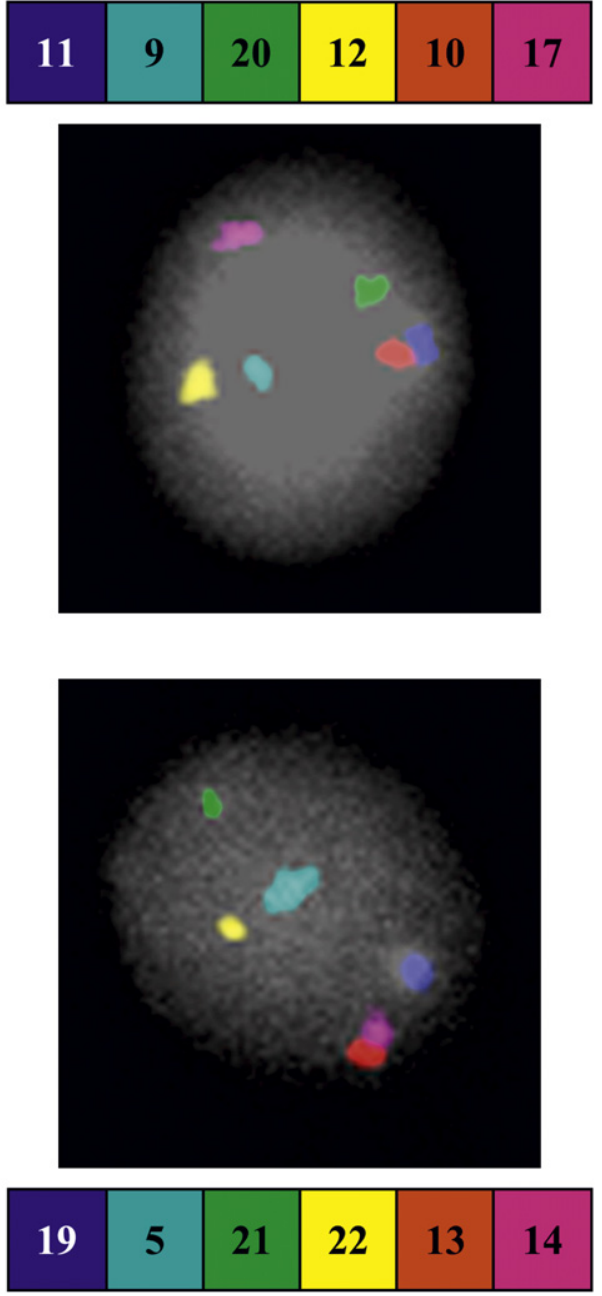

\section{Discussion}

We have described the development of an assay to detect 24 chromosome copy number on individual interphase nuclei. The advantage of this approach is that we have eliminated the need for fluorochrome mixing and that the probes have smaller and more concise hybridisation foci than previously reported studies. This has the effect of drastically reducing the likelihood of overlapping FISH signals that, in the past, has complicated and/or inhibited analysis of chromosome copy number. Another advance is the considerably shorter hybridisation period of $30 \mathrm{~min}$ for the alpha, beta and gamma layers leading to a protocol that can be performed in less than $24 \mathrm{~h}$. A bespoke capturing system, with two filter wheels and adaptations to the software was developed to capture all seven fluorochromes (including DAPI) required. We demonstrate its utility in lymphocytes, sperm and human preimplantation embryos however it could easily find utility in cancer research and diagnostics also. That is, both cancer cell lines and tumour specimens can show evidence of ploidy differences from cell to cell $[3,45,47]$. The approach described here would provide the basis by which these cell types could be analysed. A study by [40] demonstrated that interphase FISH on uncultured cells of children with lymphoblastoid leukaemia (ALL) was a more sensitive method to detect specific numerical aberrations, gene rearrangements, deletions and amplifications of diagnostic and prognostic importance than FISH on metaphase chromosomes from cultured cells. Adaptations of the approach might also be used for the determination of the order of individual sequences (e.g. BACs in interphase nuclei $[7,44]$ or for fibre FISH [10,32,48,55,56]).

The ability to evaluate copy number for all chromosomes in individual cells allows preliminary investigations into whether there are chromosome-specific mechanisms of error (i.e. is there a greater likelihood of certain chromosomes to be involved in mal-segregation event). In addition, through radial position measurements, we can study the nuclear architecture (i.e. chromosome position) in sperm and embryos and investigate any alterations in the position of chromosomes in the sperm of infertile men [13] and in preimplantation embryos $[12,14]$. Currently we are analysing the results from applying this method in a large cohort of human preimplantation embryos ( $>1000$ ), from different developmental stages (e.g. morula, blastocyst), and comparing the results with the initial diagnosis of single blastomeres biopsied on day three post-fertilisation.

A potential drawback from the current 24 chromosome screening comes from the incorporation of the Far Red fluorochrome, which is not visible to the naked eye. This could be a problem in the clinical setting (for instance diagnosing chromosome copy number in sperm or preimplantation embryos) if operators are unused to scoring signals that they cannot see. However in the recent ESHRE (European Society for Human Reproduction and Embryology) guidelines for FISH-based preimplanatation genetic screening, use of a fluorochrome not visible by the eye is considered acceptable as long as there is appropriate image capture system [24]. 

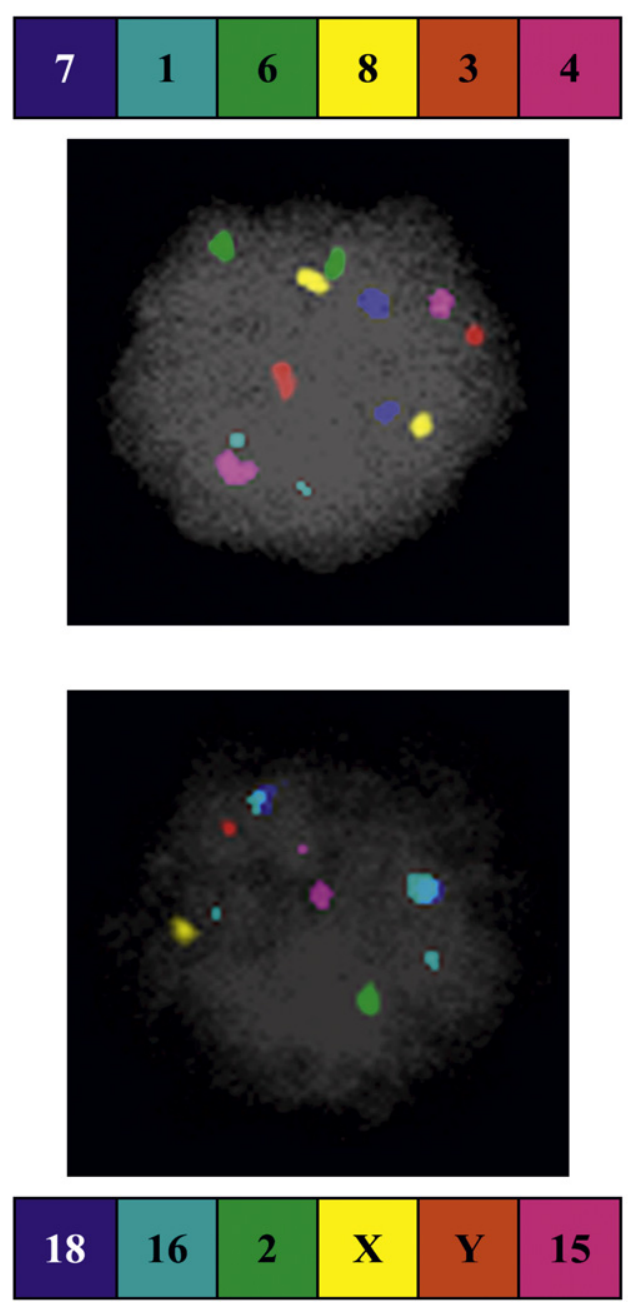
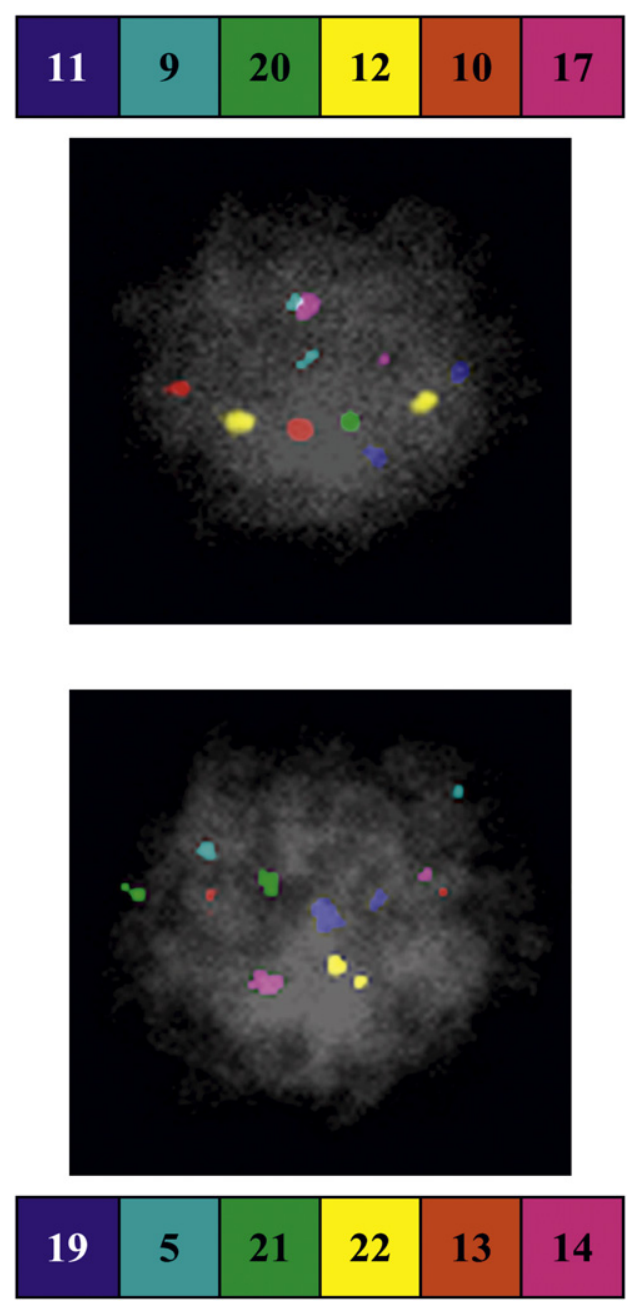

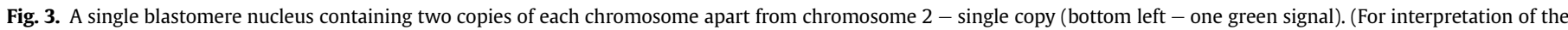
references to colour in this figure legend, the reader is referred to the web version of this article.)

It is also worth noting, that, even with these hybridisation success rates, further improvement in the omega layer would lead to greater diagnostic accuracy and this will form the basis of future studies. It point of fact, the lower hybridisation efficiency overall is mostly due to the chromosome 14 probe, which could be replaced or improved.

In conclusion, the approach described here is a technical advance on those that came before it (e.g. [34]) as it provides the basis for accurate chromosome copy number in individual nuclei. That is, re-hybridisation successes were high in previous work (e.g. [34]) however, we have taken the technology a step further and provided estimates of the reliability of diagnosing the correct ploidy for each chromosome pair. The main application for this approach is when there are few, but not necessarily single, cells and where each of those cells might be expected to have a different chromosome copy number. Typical examples are cancer cells and preimplantation embryos. When studying sperm cells the approach is also useful although there is usually no need to re-probe the slides as there are sufficient cells to be able to analyse each probe set individually. The potential is considerable for adaptations of this approach to be applied to other animals, for gene mapping, for cancer studies and in the field of reproductive medicine.

\section{References}

[1] Abruzzo MA, Griffin DK, Millie EA, Sheean LA, Hassold TJ. The effect of Y-chromosome alpha-satellite array length on the rate of sex chromosome disomy in human sperm. Hum Genet 1996;97:819-23.
[2] Arnold N, Wienberg J, Ermert K, Zachau HG. Comparative mapping of DNA probes derived from the $\mathrm{V}$ kappa immunoglobulin gene regions on human and great ape chromosomes by fluorescence in situ hybridisation. Genomics 1995;26:147-50.

[3] Camps J, Ponsa I, Ribas M, Prat E, Egozcue J, Peinado MA, et al. Comprehensive measurement of chromosomal instability in cancer cells: combination of fluorescence in situ hybridisation and cytokinesis-block micronucleus assay. FASEB J 2005;19:828-30.

[4] Celeda D, Bettag U, Cremer C. A simplified combination of DNA probe preparation and fluorescence in situ hybridisation. Z Naturforsch C 1992;47: 739-47.

[5] Cremer T, Landegent J, Bruckner A, Scholl HP, Schardin M, Hager HD, et al. Detection of chromosome aberrations in the human interphase nucleus by visualization of specific target DNAs with radioactive and non-radioactive in situ hybridisation techniques: diagnosis of trisomy 18 with probe L1.84. Hum Genet 1986;74:346-52.

[6] Dauwerse JG, Wiegant J, Raap AK, Breuning MH, van Ommen GJ. Multiple colors by fluorescence in situ hybridisation using ratio-labelled DNA probes create a molecular karyotype. Hum Mol Genet 1992;1:593-8.

[7] DeSilva U, Massa H, Trask BJ, Green ED. Comparative mapping of the region of human chromosome 7 deleted in Williams syndrome. Genome Res 1999;9: 428-36.

[8] Egozcue J, Blanco J, Vidal F. Chromosome studies in human sperm nuclei using fluorescence in-situ hybridisation (FISH). Hum Reprod Update 1997;3: 441-52.

[9] Emmerich P, Jauch A, Hofmann MC, Cremer T, Walt H. Interphase cytogenetics in paraffin embedded sections from human testicular germ cell tumor xenografts and in corresponding cultured cells. Lab Invest 1989;61:235-42.

[10] Ersfeld K. Fiber-FISH: fluorescence in situ hybridisation on stretched DNA. Methods Mol Biol 2004;270:395-402.

[11] Fiegler H, Carr P, Douglas EJ, Burford DC, Hunt S, Scott CE, et al. DNA microarrays for comparative genomic hybridisation based on DOP-PCR amplification of BAC and PAC clones. Genes Chromosomes Cancer 2003; 36:361-74. 
[12] Finch KA, Fonseka G, Ioannou D, Hickson N, Barclay Z, Chatzimeletiou K, et al. Nuclear organisation in totipotent human nuclei and its relationship to chromosomal abnormality. J Cell Sci 2008a;121:655-63.

[13] Finch KA, Fonseka KG, Abogrein A, Ioannou D, Handyside AH, Thornhill AR et al. Nuclear organization in human sperm: preliminary evidence for altered sex chromosome centromere position in infertile males. Hum Reprod 2008b; 23:1263-70

[14] Foster HA, Bridger JM. The genome and the nucleus: a marriage made by evolution. Genome organisation and nuclear architecture. Chromosoma 2005; 114:212-29.

[15] Gabriel AS, Hassold TJ, Thornhill AR, Affara NA, Handyside AH, Griffin DK. An algorithm for determining the origin of trisomy and the positions of chiasmata from SNP genotype data. Chromosome Res 2011;19:155-63.

[16] Griffin DK. Fluorescent in situ hybridisation for the diagnosis of genetic disease at postnatal, prenatal, and preimplantation stages. Int Rev Cytol 1994 153:1-40.

[17] Griffin DK, Abruzzo MA, Millie EA, Feingold E, Hassold TJ. Sex ratio in normal and disomic sperm: evidence that the extra chromosome 21 preferentially segregates with the Y chromosome. Am J Hum Genet 1996;59:1108-13.

[18] Griffin DK, Abruzzo MA, Millie EA, Sheean LA, Feingold E, Sherman SL, et al. Non-disjunction in human sperm: evidence for an effect of increasing paternal age. Hum Mol Genet 1995;4:2227-32.

[19] Griffin DK, Handyside AH, Penketh RJ, Winston RM, Delhanty JD. Fluorescent in-situ hybridisation to interphase nuclei of human preimplantation embryos with X and Y chromosome specific probes. Hum Reprod 1991;6:101-5.

[20] Griffin DK, Wilton LJ, Handyside AH, Atkinson GH, Winston RM, Delhanty JD. Diagnosis of sex in preimplantation embryos by fluorescent in situ hybridisation. BMJ 1993;306:1382.

[21] Handyside AH, Harton GL, Mariani B, Thornhill AR, Affara NA, Shaw MA, et al Karyomapping: a universal method for genome wide analysis of genetic disease based on mapping crossovers between parental haplotypes. J Med Genet; 2009.

[22] Harper JC, Coonen E, Ramaekers FC, Delhanty JD, Handyside AH, Winston RM, et al. Identification of the sex of human preimplantation embryos in two hours using an improved spreading method and fluorescent in-situ hybridisation (FISH) using directly labelled probes. Hum Reprod 1994;9:721-4.

[23] Harper JC, Harton G. The use of arrays in preimplantation genetic diagnosis and screening. Fertil Steril; 2010.

[24] Harton GL, Harper JC, Coonen E, Pehlivan T, Vesela K, Wilton L. ESHRE PGD consortium best practice guidelines for fluorescence in situ hybridisationbased PGD. Hum Reprod; 2010.

[25] Jauch A, Daumer C, Lichter P, Murken J, Schroeder-Kurth T, Cremer T. Chromosomal in situ suppression hybridisation of human gonosomes and autosomes and its use in clinical cytogenetics. Hum Genet 1990;85: 145-50.

[26] Julien C, Bazin A, Guyot B, Forestier F, Daffos F. Rapid prenatal diagnosis of Down's syndrome with in-situ hybridisation of fluorescent DNA probes. Lancet 1986;2:863-4.

[27] Kallioniemi A, Kallioniemi OP, Sudar D, Rutovitz D, Gray JW, Waldman F, et al. Comparative genomic hybridisation for molecular cytogenetic analysis of solid tumors. Science 1992;258:818-21.

[28] Kearns WG, Pen R, Benner A, Kittai A, Widra E, Leach R. SNP microarray genetic analyses to determine 23-chromosome ploidy, structural chromosome aberrations and genome-wide scans to identify disease risks from a single embryonic cell. Fertil Steril 2008;90.

[29] Kolluri RV, Manuelidis L, Cremer T, Sait S, Gezer S, Raza A. Detection of monosomy 7 in interphase cells of patients with myeloid disorders. Am J Hematol 1990;33:117-22.

[30] Langer S, Kraus J, Jentsch I, Speicher MR. Multicolor chromosome painting in diagnostic and research applications. Chromosome Res 2004;12:15-23.

[31] Lichter JB, Difilippantonio MJ, Pakstis AJ, Goodfellow PJ, Ward DC, Kidd KK. Physical and genetic maps for chromosome 10. Genomics 1993;16:320-4.

[32] Mann SM, Burkin DJ, Grin DK, Ferguson-Smith MA. A fast, novel approach for DNA fibre-fluorescence in situ hybridisation analysis. Chromosome Res 1997; 5:145-7.

[33] Matsuzaki H, Dong S, Loi H, Di X, Liu G, Hubbell E, et al. Genotyping over 100,000 SNPs on a pair of oligonucleotide arrays. Nat Methods 2004;1:109-11.

[34] Muller S, Neusser M, Wienberg J. Towards unlimited colors for fluorescence in-situ hybridisation (FISH). Chromosome Res 2002;10:223-32.
[35] Munne S, Alikani M, Tomkin G, Grifo J, Cohen J. Embryo morphology, developmental rates, and maternal age are correlated with chromosome abnormalities. Fertil Steril 1995;64:382-91.

[36] Munne S, Bahce M, Sandalinas M, Escudero T, Marquez C, Velilla E, et al. Differences in chromosome susceptibility to aneuploidy and survival to first trimester. Reprod Biomed Online 2004;8:81-90.

[37] Munne S, Grifo J, Cohen J, Weier HU. Chromosome abnormalities in human arrested preimplantation embryos: a multiple-probe FISH study. Am J Hum Genet 1994;55:150-9.

[38] Munne S, Weier HU, Stein J, Grifo J, Cohen J. A fast and efficient method for simultaneous $\mathrm{X}$ and $\mathrm{Y}$ in situ hybridisation of human blastomeres. J Assist Reprod Genet 1993;10:82-90.

[39] Nederlof PM, Robinson D, Abuknesha R, Wiegant J, Hopman AH, Tanke HJ, et al. Three-color fluorescence in situ hybridisation for the simultaneous detection of multiple nucleic acid sequences. Cytometry 1989;10:20-7.

[40] Nordgren A, Schoumans J, Soderhall S, Nordenskjold M, Blennow E. Interphase fluorescence in situ hybridisation and spectral karyotyping reveals hidden genetic aberrations in children with acute lymphoblastic leukaemia and a normal banded karyotype. Br J Haematol 2001;114:786-93.

[41] O'Keefe CL, Griffin DK, Bean CJ, Matera AG, Hassold TJ. Alphoid variant-specific FISH probes can distinguish autosomal meiosis I from meiosis II nondisjunction in human sperm. Hum Genet 1997;101:61-6.

[42] Olszewska M, Wiland E, Kurpisz M. Positioning of chromosome 15, 18, X and $\mathrm{Y}$ centromeres in sperm cells of fertile individuals and infertile patients with increased level of aneuploidy. Chromosome Res 2008;16:875-90.

[43] Pinkel D, Gray JW, Trask B, van den Engh G, Fuscoe J, van Dekken H. Cytogenetic analysis by in situ hybridisation with fluorescently labeled nucleic acid probes. Cold Spring Harb Symp Quant Biol 1986;51(Pt 1):151-7.

[44] Quilter CR, Nathwani N, Conway GS, Stanhope R, Ralph D, Bahadur G, et al. A comparative study between infertile males and patients with Turner syndrome to determine the influence of sex chromosome mosaicism and the breakpoints of structurally abnormal Y chromosomes on phenotypic sex. J Med Genet 2002;39:e80.

[45] Rennstam K, Baldetorp B, Kytola S, Tanner M, Isola J. Chromosomal rearrangements and oncogene amplification precede aneuploidization in the genetic evolution of breast cancer. Cancer Res 2001;61:1214-9.

[46] Roberts I, Wienberg J, Nacheva E, Grace C, Griffin D, Coleman N. Novel method for the production of multiple colour chromosome paints for use in karyotyping by fluorescence in situ hybridisation. Genes Chromosomes Cancer 1999;25:241-50.

[47] Rodriguez E, Mathew S, Mukherjee AB, Reuter VE, Bosl GJ, Chaganti RS. Analysis of chromosome 12 aneuploidy in interphase cells from human male germ cell tumors by fluorescence in situ hybridisation. Genes Chromosomes Cancer 1992;5:21-9.

[48] Rottger S, Yen PH, Schempp W. A fiber-FISH contig spanning the non-recombining region of the human Y chromosome. Chromosome Res 2002;10:621-35.

[49] Sbracia M, Baldi M, Cao D, Sandrelli A, Chiandetti A, Poverini R, et al. Preferential location of sex chromosomes, their aneuploidy in human sperm, and their role in determining sex chromosome aneuploidy in embryos after ICSI. Hum Reprod 2002;17:320-4.

[50] Schardin M, Cremer T, Hager HD, Lang M. Specific staining of human chromosomes in Chinese hamster x man hybrid cell lines demonstrates interphase chromosome territories. Hum Genet 1985;71:281-7.

[51] Schrock E, du Manoir S, Veldman T, Schoell B, Wienberg J, FergusonSmith MA, et al. Multicolor spectral karyotyping of human chromosomes. Science 1996;273:494-7.

[52] Speicher MR, Gwyn Ballard S, Ward DC. Karyotyping human chromosomes by combinatorial multi-fluor FISH. Nat Genet 1996;12:368-75.

[53] Syvanen AC. Toward genome-wide SNP genotyping. Nat Genet 2005;37(Suppl): S5-10.

[54] Tempest HG, Homa ST, Zhai XP, Griffin DK. Significant reduction of sperm disomy in six men: effect of traditional Chinese medicine? Asian J Androl 2005;7:419-25.

[55] Tsuchiya D, Taga M. Fluorescence in situ hybridisation for molecular cytogenetic analysis in filamentous fungi. Methods Mol Biol 2010;638:235-57.

[56] Walling JG, Pires JC, Jackson SA. Preparation of samples for comparative studies of plant chromosomes using in situ hybridisation methods. Methods Enzymol 2005;395:443-60.

[57] Wienberg J, Stanyon R. Chromosome painting in mammals as an approach to comparative genomics. Curr Opin Genet Dev 1995:5:792-7. 